\title{
Logistic regression analysis for the identification of the metastasis-associated signaling pathways of osteosarcoma
}

\author{
YANG LIU ${ }^{1}$, WEI SUN ${ }^{2}$, XIAOJUN MA ${ }^{2}$, YUEDONG HAO ${ }^{3}$, GANG LIU $^{3}$, XIAOHUI HU $^{3}$, \\ HOULAI SHANG ${ }^{3}$, PENGFEI WU ${ }^{3}$, ZEXUE ZHAO ${ }^{3}$ and WEIDONG LIU ${ }^{3}$
}

\author{
${ }^{1}$ Department of Orthopedics, Affiliated Hospital of Inner Mongolia University for The Nationalities, Tongliao, \\ Inner Mongolia 028007; ${ }^{2}$ Department of Orthopaedics, Shanghai General Hospital, School of Medicine, Shanghai Jiao Tong \\ University, Shanghai 200080; ${ }^{3}$ Department of Orthopedics, Huai'an First People's Hospital, \\ Nanjing Medical University, Huai'an, Jiangsu 223300, P.R. China
}

Received February 20, 2017; Accepted September 26, 2017

DOI: $10.3892 / \mathrm{ijmm} .2018 .3360$

\begin{abstract}
Osteosarcoma (OS) is the most common histological type of primary bone cancer. The present study was designed to identify the key genes and signaling pathways involved in the metastasis of OS. Microarray data of GSE39055 were downloaded from the Gene Expression Omnibus database, which included 19 OS biopsy specimens before metastasis (control group) and 18 OS biopsy specimens after metastasis (case group). After the differentially expressed genes (DEGs) were identified using the Linear Models for Microarray Analysis package, hierarchical clustering analysis and unsupervised clustering analysis were performed separately, using orange software and the self-organization map method. Based upon the Database for Annotation, Visualization and Integrated Discovery tool and Cytoscape software, enrichment analysis and protein-protein interaction (PPI) network analysis were conducted, respectively. After function deviation scores were calculated for the significantly enriched terms, hierarchical clustering analysis was performed using Cluster 3.0 software. Furthermore, logistic regression analysis was used to identify the terms that were significantly different. Those terms that were significantly different were validated using other independent datasets. There were 840 DEGs in the case group. There were various interactions in the PPI network [including intercellular adhesion molecule-1 (ICAM1), transforming growth factor $\beta 1$ (TGFB1), TGFB1-platelet-derived growth factor subunit $\mathrm{B}$ (PDGFB) and PDGFB-platelet-derived growth factor receptor- $\beta$ (PDGFRB)]. Regulation of cell migration, nucleotide excision repair, the Wnt signaling pathway and cell
\end{abstract}

Correspondence to: Dr Weidong Liu, Department of Orthopedics, Huai'an First People's Hospital, Nanjing Medical University, 6 Beijing Road West, Huai'an, Jiangsu 223300, P.R. China

E-mail: 1wdhayy@126.com

Key words: osteosarcoma, differentially expressed genes, proteinprotein interaction network, function deviation score migration were identified as the terms that were significantly different. ICAMI, PDGFB, PDGFRB and TGFBI were identified to be enriched in cell migration and regulation of cell migration. Nucleotide excision repair and the Wnt signaling pathway were the metastasis-associated pathways of OS. In addition, ICAM1, PDGFB, PDGFRB and TGFB1, which were involved in cell migration and regulation of cell migration may affect the metastasis of OS.

\section{Introduction}

As a cancerous tumor that originates from bone, osteosarcoma (OS) is the most frequent histological type of primary bone cancer (1). It is usually derived from tubular long bones, with $10 \%$ occurring in the humerus, $19 \%$ in the tibia and $42 \%$ in the femur (2). OS is the eighth most common type of cancer in pediatric patients, accounting for $\sim 20 \%$ of all primary bone cancers and $2.4 \%$ of all malignancies in children (3). OS usually occurs in young adults and teenagers, and may be treated by surgical resection of the cancer (4). Although $90 \%$ of OS patients undergo limb-salvage surgery, the subsequent complications (such as infection, local tumor recurrence, prosthetic non-union and loosening) may result in further surgery or amputation (5). Thus, revealing the underlying mechanisms of OS is considered to be important for improving therapeutic strategies.

Through activating the phosphatidylinositol 3-kinase (PI3K)/Akt signaling pathway, metastasis-associated lung adenocarcinoma transcript 1 contributes to proliferation and metastasis of OS and serves as a therapeutic target for OS patients (6,7).Transforming growthfactor- $\alpha$ (TGF- $\alpha$ )/epidermal growth factor receptor (EGFR) interaction induces the activation of PI3K/Akt and nuclear factor- $\mathrm{KB}(\mathrm{NF}-\mathrm{\kappa B})$ signaling pathways, leading to intracellular cell adhesion molecule 1 (ICAM1) expression and promoting the metastasis of human OS cells (8). The low expression level of monocarboxylate transporter isoform 1 ( $M C T 1$ ) performs an antitumor role via the NF-kB signaling pathway, and the high expression level of $M C T 1$ predicts poor overall survival in OS patients (9). As a negative regulator of Wnt signaling, naked cuticle homolog 2 functions in inhibiting tumor growth and invasion of human 
OS $(10,11)$. Via activation of the cyclooxygenase-2 (COX-2) gene, p50-associated COX-2 extragenic RNA promotes the proliferation and invasion of OS cells (12). Although these studies have investigated the underlying mechanisms of OS metastasis, the key genes and signaling pathways involved in the metastasis of OS have not been fully reported.

In 2013, Kelly et al (13) performed formalin-fixed, paraffin-embedded assays to identify the miRNA biomarkers associated with OS prognosis, finding that the 14q32 locus was potential involved in the progression and outcome of OS. Using the data deposited by Kelly et al (13), the differentially expressed genes (DEGs) were identified between the OS biopsy specimens following metastasis and the OS biopsy specimens prior to metastasis. Subsequently, comprehensive bioinformatics analyses [including clustering analysis, enrichment analysis, protein-protein network (PPI) analysis, calculation of function deviation score and logistic regression analysis] were performed to identify the metastasis-associated terms. Finally, the metastasis-associated terms were further confirmed by other independent datasets.

\section{Materials and methods}

Microarray data. Gene expression profiling and clinical outcomes under GSE39055 were downloaded from the Gene Expression Omnibus database (GEO; http://www.ncbi.nlm. nih.gov/geo/) database, which was based on the GEO platform, GPL14951, Illumina HumanHT-12 WG-DASL v4.0 R2 expression BeadChip. GSE39055 included 19 OS biopsy specimens before metastasis and 18 OS biopsy specimens after metastasis. The samples were acquired from the pathology archives of Boston Children's Hospital (Boston, USA) and Beth Israel Deaconess Medical Center (Boston, USA). Kelly et al (13) deposited GSE39055, and the study obtained the approval of the Institutional Review Boards at Boston Children's Hospital and Beth Israel Deaconess Medical Center with a waiver of consent.

DEG screening and clustering analysis. Based on the platform annotation information, all probe IDs were transformed into gene symbols. When one gene symbol corresponded to multiple probes, the gene expression value was obtained by calculating the average value of the probes. Subsequently, Z-score normalization was performed for all gene expression values. Using the Linear Models for Microarray Analysis package (http://www.bioconductor.org/packages/release/ bioc/html/limma.html) (14) in R, the DEGs between the OS biopsy specimens after metastasis (case group) and the OS biopsy specimens before metastasis (control group) were analyzed. $\mathrm{P}<0.05$ and $\mid \operatorname{logFC}$ (fold change) $\mid>0.6$ were set as the thresholds.

To confirm whether the DEGs were able to effectively distinguish between the two groups of samples, hierarchical clustering analysis was conducted using Orange software (version 3.4, http://orange.biolab.si/citation/) (15) and the result was visualized using a distance map (16). Pearson correlation coefficient (17) and average linkage (18) were performed separately for similarity algorithms and similarity matrices. Additionally, unsupervised clustering analysis was conducted for the samples using the self-organization map (SOM) method (19).
Functional and pathway enrichment analysis. The Gene Ontology (GO; http://www.geneontology.org) database provides information regarding cellular components (CCs), molecular function (MF), and biological processes (BPs) for gene produces (20). The Kyoto Encyclopedia of Genes and Genomes (KEGG; http://www.genome.ad.jp/kegg) is a database applied for conducting pathway analysis for genes or other molecules (21). Based on the Database for Annotation, Visualization and Integrated Discovery (DAVID; https://david.ncifcrf.gov/) tool (22), GO functional and KEGG pathway enrichment analyses were performed for the DEGs, with the threshold set at $\mathrm{P}<0.05$.

PPI network analysis. Biological General Repository for Interaction Datasets (BioGrid; http://www.thebiogrid.org) is an interaction database that includes genetic and protein interactions for humans and all major model organism species (23). Human Protein Reference Database (HPRD; http://www.hprd.org/) is a comprehensive protein information resource that provides various features of human proteins (24). The PPI network data in BioGrid (23) and HPRD (24) databases were downloaded and merged. Then, the DEGs were mapped into the human PPI network to identify the PPIs among the DEGs. Subsequently, the PPI network for the DEGs was visualized using Cytoscape software (version 3.5.0, http://www.cytoscape.org) (25). In addition, the network analysis plug-in in Cytoscape software (25) was used to analyze network topological features to screen the hub nodes (26) in the PPI network.

Calculation of function deviation score. To obtain the results with stability and accuracy, function deviation scores were calculated for the significantly enriched terms. The formula was follows:

$$
\text { function score }=\log \frac{\sqrt{\sum_{i}^{m} \omega_{i}\left(d_{i}-\bar{d}_{\imath}\right)^{2}}}{\sqrt{\sum_{j}^{n} \omega_{j}\left(d_{j}-\bar{d}_{j}\right)^{2}}}
$$

Where $\mathrm{m}$ and $\mathrm{n}$ separately represent the numbers of upregulated and downregulated genes enriched in term P. $\bar{d}$ represents the mean value of the upregulated gene, $i$ or downregulated gene, $\mathrm{j}$ in the control group. $\omega$ represents the node degree of a gene in the PPI network. The Euclidean distance is used to calculate the degree of deviation of the term $\mathrm{P}$ influenced by the upregulated and downregulated genes. Function score $>0$ indicates that the term $\mathrm{P}$ is upregulated in the case group compared with the control group. Function score $<0$ indicates that the term $\mathrm{P}$ is downregulated in the case group compared with the control group. Combined with the function deviation scores, hierarchical clustering analysis was performed using Cluster 3.0 software (27) to verify whether these significantly enriched terms clearly distinguished the case group from the control group.

Identification of significantly different terms. To identify the terms with significant differences in OS biopsy specimens before/after metastasis, logistic regression analysis was performed to calculate the significance of each term. The terms with $\mathrm{P}<0.05$ were considered to be significantly different (also defined as metastasis-associated terms). 
A

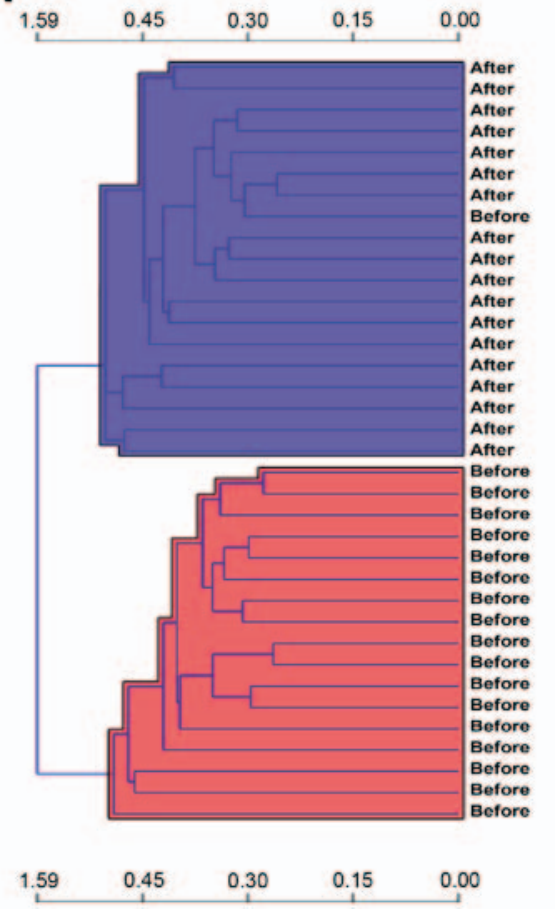

B

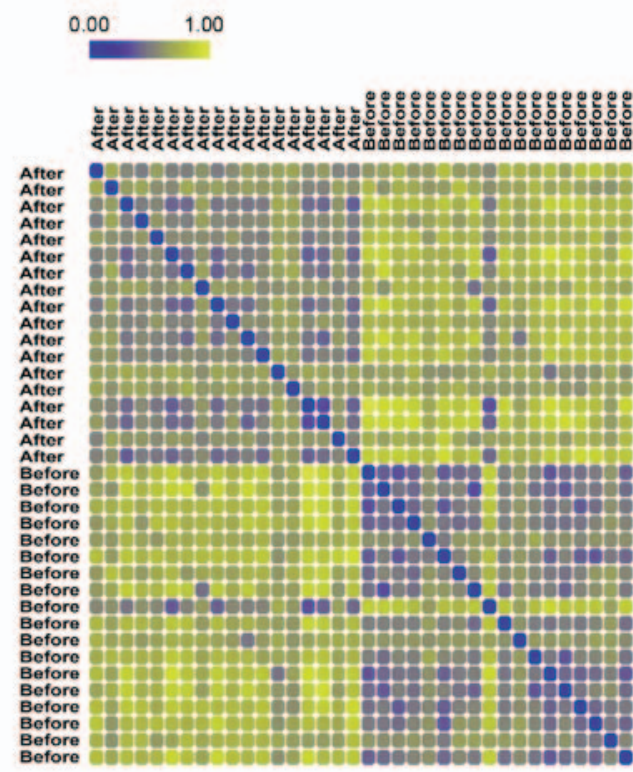

Figure 1. (A) Heat map of hierarchical clustering analysis (horizontal and vertical axes represent similarity distance and OS biopsy specimens before/after metastasis, respectively). (B) Distance map demonstrating the distances between the remaining 36 samples (blue and yellow separately represent close and far distances, respectively). OS, osteosarcoma.

Validation of the metastasis-associated terms using other independent datasets. Two microarray datasets, GSE21257 (including 19 OS specimens without metastasis and 34 OS specimens with metastasis) and GSE32981 (including five OS specimens without metastasis and 18 OS specimens with metastasis) were downloaded from the European Molecular Biology Laboratory (http://www.ebi.ac.uk/embl/index.html) Nucleotide Sequence Database. Subsequently, the two datasets were merged and normalized. The OS specimens with/without metastasis were predicted, and the prediction accuracy was exhibited via receiver operating characteristic (ROC) curves. In addition, Kaplan-Meier (KM) survival analysis (28) was used to analyze the correlations between the survival times in GSE21257 and GSE16091 (downloaded from the GEO database) and the metastasis-associated terms.

The main risk factor for disease recurrence and metastasis is the sensitivity of patients to drug treatment, and metastasis/recurrence typically occurs when there is apparent drug resistance (29). Microarray data of GSE81892 (including 21 OS specimens with obvious resistance and 13 OS specimens with drug sensitivity) and GSE14827 (including 16 OS specimens with obvious resistance and 11 OS specimens with drug sensitivity) were downloaded from the GEO database. To confirm whether the metastasis-associated terms affect drug sensitivity and influence the risk of metastasis/recurrence, the terms were used to distinguish the OS specimens with obvious resistance and the OS specimens with drug sensitivity.

\section{Results}

DEG analysis. A total of 840 DEGs were identified in the case group compared with the control group, including
420 upregulated genes and 420 downregulated genes. After removing one abnormal sample, the remaining 36 samples were used for the subsequent analysis. Hierarchical clustering analysis demonstrated that 19 samples were included in the case group (accuracy, 95\%) and 17 samples were included in the control group (accuracy, 100\%) (Fig. 1A). To further evaluate the correlation and distance between the two groups of samples, the distances between the remaining 36 samples were visualized using a distance map (Fig. 1B). The distances between the intra-group samples tended to be closer, while the distances between the inter-group samples were relatively far apart. Meanwhile, unsupervised clustering analysis based on the SOM method demonstrated that the classification effect for the samples in the majority of neurons was good (Fig. 2).

Functional and pathway enrichment analysis. The upregulated and downregulated genes separately underwent enrichment analysis. The GO terms that were enriched for the upregulated genes predominantly included regulation of cell migration $(\mathrm{P}=2.83 \mathrm{E}-12)$, blood vessel development $(\mathrm{P}=2.74 \mathrm{E}-10)$ and vasculature development $(\mathrm{P}=4.67 \mathrm{E}-10)$ (Table I). The upregulated genes were enriched in the KEGG pathways of viral myocarditis $(\mathrm{P}=7.85 \mathrm{E}-08)$, focal adhesion $(\mathrm{P}=3.70 \mathrm{E}-06)$ and endocytosis $(\mathrm{P}=1.44 \mathrm{E}-03)$ (Table II). In addition, the downregulated genes were predominantly enriched in the GO terms of RNA metabolic processes $(\mathrm{P}=1.11 \mathrm{E}-06)$, RNA processing $(\mathrm{P}=2.11 \mathrm{E}-06)$ and regulation of gene expression $(\mathrm{P}=5.20 \mathrm{E}-04)$ (Table III). Furthermore, the KEGG pathways enriched for the downregulated genes were cell adhesion molecules $(\mathrm{P}=2.32 \mathrm{E}-09)$, extracellular matrix-receptor interaction $(\mathrm{P}=1.49 \mathrm{E}-08)$, and pathways in cancer $(\mathrm{P}=3.04 \mathrm{E}-02)$ (Table IV). 
Table I. The Gene Ontology (GO) terms significantly enriched for the upregulated genes.

\begin{tabular}{|c|c|c|c|}
\hline Term & Count & P-value & Gene symbol \\
\hline $\begin{array}{l}\text { GO:0030334 - } \\
\text { regulation of } \\
\text { cell migration }\end{array}$ & 25 & $2.83 \mathrm{E}-12$ & $\begin{array}{l}D L C 1, P D G F B, E N P P 2, K I T, A D A, T G F B 1, A C E, S 1 P R 1, I N S, T E K, \text { ROBO4, } \\
\text { TIE1,LAMB1,ICAM1, PTPRM, IGF2, VASH1,THY1, KDR, LAMA4, LAMA3, } \\
\text { CLIC4, PDGFRB, ARAP3,IGFBP3, F2R }\end{array}$ \\
\hline $\begin{array}{l}\text { GO:0001568 - blood } \\
\text { vessel development }\end{array}$ & 27 & $2.74 \mathrm{E}-10$ & $\begin{array}{l}\text { EMCN }, C A V 1, A T P 5 B, C O L 3 A 1, \text { WASF } 2, E L K 3, C D H 5, \text { GJC1, PTK2, ACE, } \\
\text { S1PR1, CD44, ROBO4,LOX, PLXND1, EPAS1, MYO1E, MMP19, COL15A1, } \\
\text { UBP1, THY1, KDR, LAMA4, BGN, PLXDC1, NOTCH4,ENG }\end{array}$ \\
\hline $\begin{array}{l}\text { GO:0001944 - } \\
\text { vasculature } \\
\text { development }\end{array}$ & 27 & $4.67 \mathrm{E}-10$ & $\begin{array}{l}\text { EMCN }, C A V 1, A T P 5 B, C O L 3 A 1, \text { WASF2, ELK3, CDH5, GJC1, PTK2, ACE, } \\
\text { S1PR1, CD44, ROBO4,LOX, PLXND1, EPAS1, MYO1E, MMP19, COL15A1, } \\
\text { UBP1, THY1, KDR, LAMA4, BGN, PLXDC1, NOTCH4, ENG }\end{array}$ \\
\hline $\begin{array}{l}\text { GO:0048514 - blood } \\
\text { vessel morphogenesis }\end{array}$ & 22 & $4.70 \mathrm{E}-08$ & $\begin{array}{l}\text { CAV1, EMCN, EPAS1, ATP5B, MYO1E, MMP19, WASF2, COL15A1, ELK3, } \\
\text { UBP1, GJC1,THY1, KDR, PTK2, ACE, S1PR1, BGN, PLXDC1, NOTCH4, } \\
\text { ROBO4, PLXND1, ENG }\end{array}$ \\
\hline $\begin{array}{l}\text { GO:0016477 - cell } \\
\text { migration }\end{array}$ & 24 & $2.82 \mathrm{E}-07$ & $\begin{array}{l}\text { ICAM1 , PDGFB, ATP5B, PODXL, WASF2, ITGA1, KIT, TGFB1, KDR, VCAM1, } \\
\text { NCK2, EDNRB, PTK2, ITGA6, CD44, CD 34, ITGA5, FYN, PDGFRB, MSN, } \\
\text { LAMC1, ENG, MYH10, THBS4 }\end{array}$ \\
\hline $\begin{array}{l}\text { GO:0007167 - enzyme } \\
\text { linked receptor protein } \\
\text { signaling pathway }\end{array}$ & 24 & $1.11 \mathrm{E}-05$ & 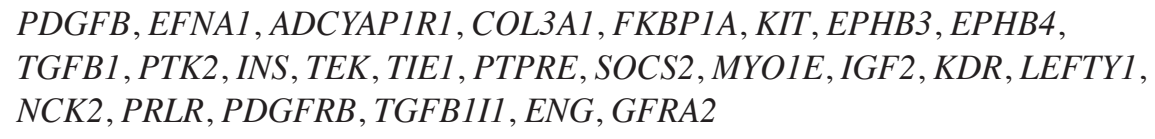 \\
\hline $\begin{array}{l}\text { GO:0009966 - } \\
\text { regulation of } \\
\text { signal transduction }\end{array}$ & 42 & $4.27 \mathrm{E}-05$ & $\begin{array}{l}\text { DLC1, FGD2, CAV1, PDGFB, TBC1D9, EFNA1, AGFG2, PREX2, ASAP2, } \\
\text { ASAP1,ITPKB, FKBP1A, KIT, CD74, MCF } 2 L, T G F B 1, A D A, S 1 P R 1, N O D 1, \\
\text { INS , RAPGEF5, RHOC, TRAF5, RAMP2, SOCS2, PSD3,ITGA1,IGF2, } \\
\text { ARHGEF15, CD40,THY1, NCK2,TNFSF10, ARRB1, RGS5, TGFB1I1, GRK5, } \\
\text { IGFBP2, ARAP3, ENG, IGFBP3, MAP3K11, F2R }\end{array}$ \\
\hline $\begin{array}{l}\text { GO:0009888 - tissue } \\
\text { development }\end{array}$ & 31 & $8.58 \mathrm{E}-04$ & $\begin{array}{l}\text { DLC1, CAV1, COL3A1, FKBP1A, TIMP3, TGFB1, GJC1, EDNRB, S1PR1, } \\
\text { CD44, SERPINE1,TIE1, F11R, BMP1, HSPG2, MECOM, SNAI2, COL5A2, } \\
\text { FZD6, KDR, NOTCH3, LAMA3, SPRR1B, NOTCH4, PDGFRB, LAMC1, } \\
\text { TGFB1I1, ENG, FABP5, F2R, MYH10 }\end{array}$ \\
\hline $\begin{array}{l}\text { GO:0008284 - } \\
\text { positive regulation } \\
\text { of cell proliferation }\end{array}$ & 22 & $1.26 \mathrm{E}-03$ & $\begin{array}{l}\text { GNAI2, PDGFB, BTC, CDK6, IGF2, KIT, CD40, PNP , ADA, TGFB1, KDR, } \\
\text { VCAM1, NCK2, S1PR1, INS, NOTCH4, AVPR1A, PDGFRB,LAMC1,LAMB1, } \\
\text { TRAF5, THPO , F2R }\end{array}$ \\
\hline $\begin{array}{l}\text { GO:0043067 - } \\
\text { regulation } \\
\text { of programmed } \\
\text { cell death }\end{array}$ & 34 & $2.71 \mathrm{E}-03$ & $\begin{array}{l}\text { DLC1, FGD2, BID, CADM1, BTC, KIT, TIMP3, ADA, TGFB1, MCF2L, CD74, } \\
\text { EDNRB, PEA15, PCGF2, NOD1, CASP4, CD44, INS, TRAF5, PHLDA1, HIP1, } \\
\text { GIMAP5, ACTN4, SOCS2,ITGA1,IGF2, NLRP1, CASP10, TNFSF10, PRLR, } \\
\text { ETS1, IGFBP3, FAIM2, F2R, MAP3K11 }\end{array}$ \\
\hline $\begin{array}{l}\text { GO:0007166- } \\
\text { cell surface } \\
\text { receptor } \\
\text { linked signal } \\
\text { transduction }\end{array}$ & 64 & $3.44 \mathrm{E}-03$ & $\begin{array}{l}\text { PDGFB, EFNA1, PREX2, WASF2, LPAR4, ITPKB, TGFB1, LPHN2, EDNRB, } \\
\text { S1PR1, ELTD1, TIE1, RAMP2, GPR176, SOCS2, CD40, OR10J1, THY1, } \\
\text { LEFTY1, NCK2, CPE, CHRM2, LPAR6, GPR56, PDGFRB, TGFB1I1, GNAI2, } \\
\text { GNAI1, ENPP2, ADCYAP1R1, COL3A1, GNG11, FKBP1A, GAST, KIT, EPHB3, } \\
\text { EPHB4, APLNR, PTK2, DOCK1, INS, TEK, PTPRE, MYO1E, ITGA1,IGF2, } \\
\text { OR51E2, CENPI, KDR, FZD6, NOTCH3, SEMA6A, LAMA3, PRLR, ITGA6, } \\
\text { FYN, ITGA5, HEYL, NOTCH4, AVPR1A, GRK5, ENG, GFRA2, GPR116, F2R }\end{array}$ \\
\hline $\begin{array}{l}\text { GO:0042981- } \\
\text { regulation } \\
\text { of apoptosis }\end{array}$ & 33 & $4.22 \mathrm{E}-03$ & $\begin{array}{l}\text { DLC1, FGD2, BID, CADM1, BTC, TIMP3, ADA, TGFB1, MCF2L, CD74, } \\
\text { EDNRB, PEA15, PCGF2, NOD1, CASP4, CD44, INS, TRAF5, PHLDA1, } \\
\text { HIP1, GIMAP5, ACTN4, SOCS2,ITGA1,IGF2, NLRP1, CASP10, TNFSF10, } \\
\text { PRLR, ETS1, IGFBP3, FAIM2, F2R, MAP3K11 }\end{array}$ \\
\hline $\begin{array}{l}\text { hsa04514: } \\
\text { Cell adhesion } \\
\text { molecules (CAMs) }\end{array}$ & 22 & 2.32E-09 & $\begin{array}{l}F 11 R, I C A M 1, \text { PTPRM, CADM1, ICAM2, CLDN5, HLA-A, HLA-C, CD40, } \\
\text { HLA-B, HLA-E, HLA-DMA, HLA-DQA1, HLA-G, CDH5, VCAM1, ITGA6, } \\
\text { CD34, PECAM1, HLA-DPA1, HLA-DPB1, JAM2, HLA-DRA }\end{array}$ \\
\hline $\begin{array}{l}\text { hsa04512: ECM- } \\
\text { receptor interaction }\end{array}$ & 17 & $1.49 \mathrm{E}-08$ & $\begin{array}{l}\text { COLAA2, COL4A1, COL3A1, ITGA1, HSPG2, COL5A2, VWF, LAMA4, } \\
\text { LAMA3, CD44, ITGA6, ITGA5, COL6A3, SV2B, LAMC1, LAMB1, THBS4 }\end{array}$ \\
\hline $\begin{array}{l}\text { hsa05200: Pathways } \\
\text { in cancer }\end{array}$ & 19 & $3.04 \mathrm{E}-02$ & $\begin{array}{l}\text { BID, COL4A2, COLAA1, PDGFB, EPAS1, CDK6, KIT, MECOM, TGFB1, FZD6, } \\
\text { PTK2, LAMA4, LAMA3, ITGA6, ETS1, PDGFRB, LAMC1,LAMB1, TRAF5 }\end{array}$ \\
\hline
\end{tabular}


Table II. The KEGG pathways significant enriched for the upregulated genes.

\begin{tabular}{|c|c|c|c|}
\hline Term & Count & P-value & Gene symbol \\
\hline $\begin{array}{l}\text { hsa04514: } \\
\text { Cell adhesion } \\
\text { molecules (CAMs) }\end{array}$ & 22 & $2.32 \mathrm{E}-09$ & $\begin{array}{l}\text { F11R, ICAM1, PTPRM, CADM1, ICAM2, CLDN5, HLA-A, HLA-C, CD40, } \\
\text { HLA- } B, \text { HLA-E, HLA-DMA, HLA-DQA1, HLA-G, CDH5, VCAM1, ITGA6, } \\
\text { CD34, PECAM1, HLA-DPA1, HLA-DPB1, JAM2, HLA-DRA }\end{array}$ \\
\hline $\begin{array}{l}\text { hsa04512: ECM- } \\
\text { receptor interaction }\end{array}$ & 17 & $1.49 \mathrm{E}-08$ & $\begin{array}{l}\text { COLAA2, COL4A1, COL3A1, ITGA1, HSPG2, COL5A2,VWF, LAMA4, } \\
\text { LAMA3, CD44, ITGA6, ITGA5, COL6A3,SV2B,LAMC1,LAMB1,THBS4 }\end{array}$ \\
\hline $\begin{array}{l}\text { hsa05200: Pathways } \\
\text { in cancer }\end{array}$ & 19 & 3.04E-02 & $\begin{array}{l}\text { BID , COLAA2, COLAA1, PDGFB, EPAS1, CDK6, KIT, MECOM, TGFB1, FZD6, } \\
\text { PTK2, LAMA4, LAMA3, ITGA6, ETS1, PDGFRB, LAMC1, LAMB1, TRAF5 }\end{array}$ \\
\hline
\end{tabular}

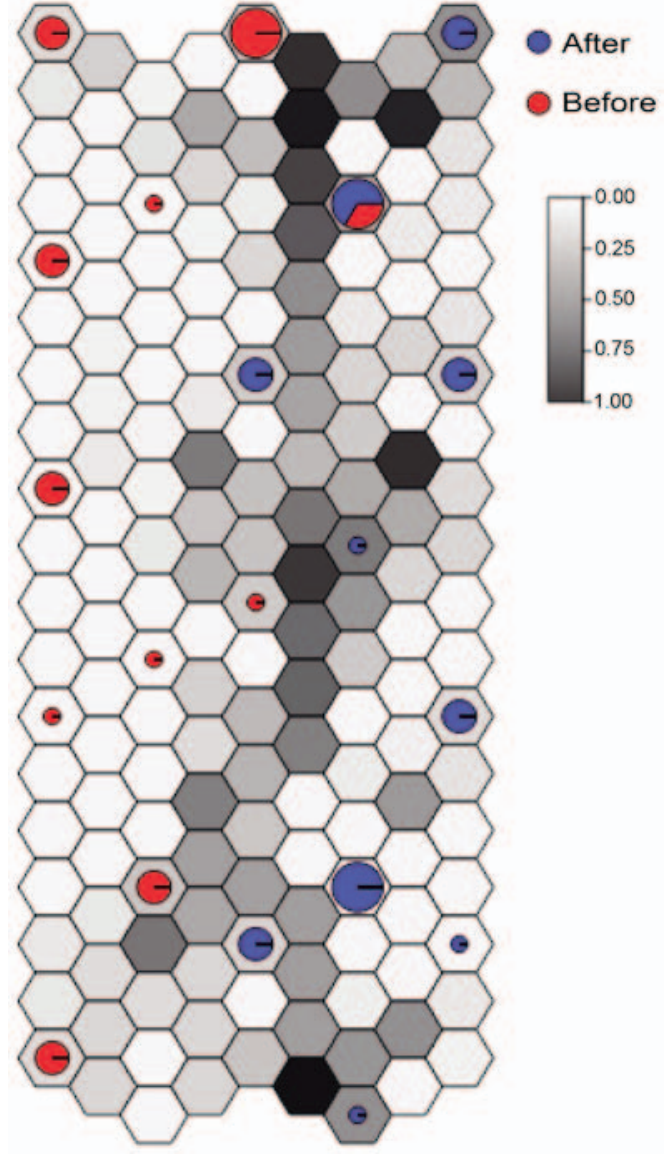

Figure 2. Result of unsupervised clustering analysis based on the self-organization map method. Red and blue represent osteosarcoma biopsy specimens before and after metastasis, respectively.

PPI network analysis and function deviation score. The PPI network for the DEGs contained 409 nodes (including 195 upregulated and 214 downregulated genes) (Fig. 3). Notably, there were various interactions [including ICAM1-TGF- $\beta 1$, TGFB1-platelet-derived growth factor $\beta$ (PDGFB), and PDGFB-platelet derived growth factor receptor $\beta$ (PDGFRB)] in the PPI network. After calculating the function deviation scores of the significantly enriched terms, hierarchical clustering analysis was performed to verify whether these terms clearly distinguished the case group from the control group. The heat map demonstrated that almost all samples were clearly distinguished, indicating that the significantly enriched terms significantly changed at the functional level during OS metastasis (Fig. 4).

Identification of significantly different terms. To identify the significantly different terms in the two groups of samples, logistic regression analysis was performed. The top 25 terms with $\mathrm{P}<0.01$ were listed in Table $\mathrm{V}$, including regulation of cell migration $(\mathrm{P}=2.15 \mathrm{E}-05)$, nucleotide excision repair $(\mathrm{P}=1.31 \mathrm{E}-05)$, Wnt signaling pathway $(\mathrm{P}=2.32 \mathrm{E}-03)$, and cell migration $(\mathrm{P}=5.56 \mathrm{E}-03)$. Specifically, ICAM1, $P D G F B$, $P D G F R B$ and $T G F B 1$ were enriched in cell migration and regulation of cell migration.

Validation of the metastasis-associated terms using other independent datasets. After the microarray datasets, GSE21257 and GSE32981 were merged and normalized, the OS specimens with/without metastasis were predicted. The ROC curves demonstrated that the prediction accuracies of the metastasis-associated terms, the genes enriched in the metastasis-associated terms, and all the DEGs were 0.875 , 0.783 and 0.803 , respectively (Fig. 5). Thus, the metastasisassociated terms optimized the number of characteristics without reducing the prediction accuracy. In addition, the KM survival curve demonstrated that the survival times of the samples with significant differences in the metastasis-associated terms were significantly changed $(\mathrm{P}=0.0279)$ (Fig. 6). In addition, a regression model was used to predict the samples in GSE81892 and GSE14827. The results demonstrated that the prediction accuracies of the model to OS specimens with obvious resistance and OS specimens with drug sensitivity were 82.4 and $65 \%$, respectively. These indicated that the metastasis-associated terms affected drug sensitivity and had better predictive effects for OS specimens with obvious resistance.

\section{Discussion}

In the present study, a total of 840 DEGs (including 420 upregulated and 420 downregulated genes) were identified in the case group compared with the control group. Unsupervised clustering analysis indicated that the classification effect for the samples in the majority of neurons was good. Hierarchical clustering analysis indicated that the significantly enriched terms significantly changed at a functional level during OS metastasis. Regulation of cell migration, nucleotide excision 
Table III. The Gene Ontology (GO) terms significant enriched for the downregulated genes.

\begin{tabular}{|c|c|c|c|}
\hline Term & Count & P-value & Gene symbol \\
\hline $\begin{array}{l}\text { GO:0016070 - RNA } \\
\text { metabolic process }\end{array}$ & 49 & $1.11 \mathrm{E}-06$ & $\begin{array}{l}\text { EIF2C2, TCOF1, SYNCRIP, SKIV2L2, WTAP, SART1, SMNDC1, INTS8, } \\
\text { IMP3, RRP1B, ASH2L, TRMT5, QKI, SUPT5H, IMP4, NFX1, KHDRBS3, } \\
\text { AR, ZCCHC11, PRPF39, MED13, HNRNPU, C4ORF } 23, \text { EIF4G1, HNRPDL, } \\
\text { CELF1, SNRPF, MYNN, CPSF3L, ELL, SR140, WBP11, HSPA1A, POLR2C, } \\
\text { PPAN, RPL7, PRKRA, C19ORF29, GTF3C5, TCEA1, SNRNP70, SNRNP35, } \\
\text { NFATC } 3, \text { PRPF4OA, SMG5, TAF7, PPP1R8, POP1, DDX54 }\end{array}$ \\
\hline
\end{tabular}

GO:0006396 - RNA

processing

GO:0010468 -

regulation of

gene expression
GO:0016071 - mRNA

metabolic process

GO:0010605 - negative regulation of macromolecule metabolic process GO:0030163 - protein catabolic process

GO:0043632 -

modification-dependent macromolecule catabolic process GO:0010629 - negative regulation of gene expression GO:0019219 regulation of nucleic acid metabolic process
$34 \quad 2.11 \mathrm{E}-06$

CPSF3L, EIF2C2, SR140, SYNCRIP, SKIV2L2, WBP11, WTAP, POLR2C, SART1, SMNDC1, INTS8, PPAN, IMP3, RRP1B, RPL7, TRMT5, PRKRA, C19ORF29, QKI, SNRNP70, SNRNP35, IMP4, PRPF40A, KHDRBS3, ZCCHC11, PRPF39, HNRNPU, C4ORF23, HNRPDL, PPP1R8, POP1, CELF1, DDX54, SNRPF

$97 \quad 5.20 \mathrm{E}-04$

EIF2C2, ARNT2, STAT5B, MORF4L2, NAA15, SYNCRIP, CNOT1, CBX7, ZNF304, CRY2, DIRAS3, MED28, SUPT5H, EIF2B4, MYST3, GTPBP4, MED13, HNRNPU, BAZ1B, ZNF238, ZNF239, MNX1, MGA, ZZZ3, CELF1, PAF1, MYNN, SIVA1, CNBP, ELL, ADORA2A, HOXA11, TH1L, CYTL1, KEAP1, NR1H2, LYL1, EIF3H, PRKRA, LHX5, DNMT3A, TAF7, ZBTB44, UIMC1, SAFB2, HDAC5, NRF1, EIF4H, ATF7, SMARCC2, RFX1, DDX54, SOX21, E2F6, MITF, CTCF, PHF20, ZKSCAN5, CRX, AES, ASH2L, ACTR5, CCDC101, ZNF 146, QKI, NFX1, ZNF281, AR, KHDRBS3, ZCCHC11, GMEB1, ZNF143, HNRPDL, EIF4G1, MED6, BPTF, CARM1, MTDH, ZBTB11, SCML1, GCN1L1, MORC3, HMGXB4, PPP3CB, TCEA1, THAP1, KDM3B, SNRNP70, NFATC3, TERF2, NACC2, CEBPE, SIRT4, ZNF669, PKNOX1, PPP1R8, RBM15

$21 \quad 9.32 \mathrm{E}-04$

EIF2C2, KHDRBS3, SMG5, SYNCRIP, PRPF39, WBP11, SKIV2L2, HSPA1A WTAP, POLR2C, HNRNPU, SART1, SMNDC1, PPP1R8, C19ORF29, QKI, CELF1, SNRNP35, SNRNP70, SNRPF, PRPF40A

$1.34 \mathrm{E}-03$

HCRT, EIF2C2, MTDH, E2F6, TH1L, CTCF, ANAPC10, NR1H2, AES, PSMB1, PRKRA, SUPT5H, TERF2, EIF2B4, MYST3, NFX1, ZNF281, DNMT3A, ANAPC2, GTPBP4, NACC2, ZCCHC11, TAF7, SIRT4, UIMC1, HDAC5, ZNF238, BPTF, PSMA5, PSMC3, SMARCC2, CELF1, RBM15

RAD23B, KIAA0368, ATG12, UBE3B, UBE2V2, ANAPC10, UBE2D3, LONP1, USP27X, PSMB1, OTUD7B, RNF167, FBXO42, FBXO9, TPRKB, CUL1, NFX1, AXIN1, ANAPC2, SOCS6, SOCS5, KCMF1, CUL4A, PSMC3, PSMA5, UBR5, SIAH1, PCYOX1, FBXO11

RAD23B, ATG12, UBE3B, KIAA0368, UBE2V2, ANAPC10, LONP1, USP27X, UBE2D3, PSMB1, OTUD7B, RNF167, FBXO42, FBXO9, CUL1, NFX1, ANAPC2, SOCS6, SOCS5, KCMF1, CULAA, PSMC3, PSMA5, UBR5, SIAH1, PCYOX1, FBXO11

3.64E-03

ZNF281, DNMT3A, EIF2C2, NACC2, ZCCHC11, MTDH, E2F6, TH1L, TAF7, SIRT4, CTCF , UIMC1, NR1H2, HDAC5, AES, ZNF238, BPTF, PRKRA, SMARCC2, CELF1, SUPT5H, RBM15, MYST3, NFX1

$91 \quad 4.03 \mathrm{E}-03$

EIF2C2, SOX21, E2F6, MORF4L2, MITF, STAT5B, ARNT2, NAA15, SYNCRIP, CNOT1, CTCF , PHF20, CBX7, ZKSCAN5, CRX, ZNF304, CRY2, AES, ASH2L, MED28, ACTR5, CCDC101, ZNF 146, SUPT5H, MYST3, NFX1, ZNF281, AR, KHDRBS3, GTPBP4, GMEB1, ZNF143, MED13, HNRNPU, MED6, HNRPDL, ZNF238, BPTF, BAZ1B, ZNF239, MNX1, MGA, ZZZ3, PAF1, CARM1, MYNN, SIVA1, HCRT, CNBP, MTDH, ADORA2A, ELL, ZBTB11, HOXA11, SCML1, PTH1R, TH1L, CYTL1, UBE2V2, KEAP1, NR1H2, LYL1, HMGXB4, LHX5, THAP1, TCEA1, KDM3B, SNRNP70, NFATC3, TERF2, GUCA1B, DNMT3A, GUCA1A, NACC2, CEBPE, TAF7, SIRT4, ZNF669, ZBTB44, UIMC1, SAFB2, HDAC5, NRF1, P2RY11, PKNOX1, PPP1R8, ATF7, SMARCC2, RFX1, DDX54, RBM15 
Table III. Continued.

\begin{tabular}{|c|c|c|c|}
\hline Term & Count & P-value & Gene symbol \\
\hline $\begin{array}{l}\text { GO: } 0044257 \text { - cellular } \\
\text { protein catabolic } \\
\text { process }\end{array}$ & 27 & $4.27 \mathrm{E}-03$ & $\begin{array}{l}\text { RAD23B, ATG12, UBE3B, KIAA0368, UBE2V2, ANAPC10, LONP1, USP27X, } \\
\text { UBE2D3, PSMB1, OTUD7B, RNF167, FBXO42, FBXO9, CUL1, NFX1, } \\
\text { ANAPC2, SOCS6, SOCS5, KCMF1, CUL4A, PSMC3, PSMA5, UBR5, SIAH1, } \\
\text { PCYOX1, FBXO11 }\end{array}$ \\
\hline
\end{tabular}

GO:0010558 - negative 25

regulation of

macromolecule

biosynthetic process

GO:0031325 - positive

regulation of cellular

metabolic

process

GO:0031327 - negative regulation of cellular biosynthetic process

GO:0031324 - negative regulation of cellular metabolic process

GO:0044267 -

cellular protein metabolic process

GO:0031326 -

regulation of cellular biosynthetic process

GO:0010604 - positive regulation of macromolecule metabolic process

GO:0045893 - positive regulation of transcription, DNA-dependent GO:0009890 - negative regulation of biosynthetic process

25

4.95E-03 HCRT, EIF2C2, MTDH, E2F6, TH1L, CTCF, NR1H2, AES, SUPT5H, EIF2B4, TERF2, NFX1, MYST3, ZNF281, DNMT3A, GTPBP4, NACC2, TAF7, SIRT4, UIMC1, HDAC5, ZNF238, BPTF, SMARCC2, RBM15

35 6.60E-03 CNBP, ADORA2A, MORF4L2, ARNT2, MITF, STAT5B, NAA15, CYTL1, CTCF, ANAPC10, CRX, NR1H2, PSMB1, TCEA1, CD24, SUPT5H, NFATC3, TERF2, CUL1, MYST3, AXIN1, ANAPC2, AR, TAF7, MED13, UIMC1, MED6, HDAC5, PKNOX1, BPTF, PSMA5, PSMC3, SMARCC2, TNK2, RBM15

$6.64 \mathrm{E}-03$

HCRT, EIF2C2, MTDH, E2F6, TH1L, CTCF , NR1H2, AES, SUPT5H, EIF2B4, TERF2, NFX1, MYST3, ZNF281, DNMT3A, GTPBP4, NACC2, TAF7, SIRT4, UIMC1, HDAC5, ZNF238, BPTF, SMARCC2, RBM15

6.85E-03 HCRT, EIF2C2, MTDH, E2F6, TH1L, CTCF, ANAPC10, NR1H2, AES, PSMB1, SUPT5H, EIF2B4, TERF2, MYST3, NFX1, ZNF281, DNMT3A, ANAPC2, GTPBP4, NACC2, TAF7, SIRT4, UIMC1, HDAC5, ZNF238, BPTF, PSMC3, PSMA5, SMARCC2, RBM15

EIF2C2, KIAA0368, NAA15, ART3, USP27X, LONP1, CRY2, FAU, SIK2, EIF2B4, CUL1, MYST3, NFX1, ANAPC2, SGK2, ROCK2, SECISBP2, SOCS6, SOCS5, DAPK3, ST13, EIF4G1, BAZ1B, PSMA5, UBR5, SIAH1, PAF1, PCYOX1, CARM1, TM4SF4, FBXO11, RAD23B, UBE3B, ATG12, STK11, BLK, CAMK2G, MAPKAPK5, ANAPC10, UBE2V2, AKAP9, MTMR3, UBE2D3, EIF3G, RPL7, PSMB1, MORC3, EIF3H, SH3GLB1, PRKRA, OTUD7B, PPP3CB, RNF167, FBXO42, RSL24D1, EIF3J, FBXO9, OBSCN, P4HB, ALPK3, RYK, EEF1A2, SIRT4, OXSR1, LOC653566, UIMC1, HDAC5, NMT1, CULAA, KCMF1, RPL13A, PSMC3, PPID, EIF4H, CCT8, LGTN, TNK2

EIF2C2, SOX21, E2F6, MORF4L2, STAT5B, ARNT2, MITF, NAA15, CNOT1, CTCF , PHF20, CBX7, ZKSCAN5, CRX, ZNF304, CRY2, AES, ASH2L, MED28, ACTR5, CCDC101, ZNF 146, QKI, SUPT5H, EIF2B4, MYST3, NFX1, ZNF281, AR, KHDRBS3, GTPBP4, GMEB1, ZNF143, MED13, MED6, HNRPDL, EIF4G1, ZNF238, BPTF, BAZ1B, ZNF239, MNX1, MGA, ZZZ3, PAF1, CARM1, MYNN, SIVA1, HCRT, CNBP, MTDH, ADORA2A, ELL, ZBTB11, HOXA11, SCML1, PTH1R, TH1L, CYTL1, KEAP1, GCN1L1, NR1H2, EIF3H, LYL1, HMGXB4, LHX5, THAP1, TCEA1, KDM3B, NFATC3, TERF2, GUCA1B, DNMT3A, GUCA1A, NACC2, CEBPE, TAF7, SIRT4, ZNF669, ZBTB44, UIMC1, SAFB2, HDAC5, NRF1, P2RY11, PKNOX1, PPP1R8, EIF4H, ATF7, SMARCC2, RFX1,DDX54, RBM15

7.79E-03

CNBP, MORF4L2, ARNT2, MITF, STAT5B, NAA15, CYTL1, CTCF, ANAPC10, CRX, NR1H2, PSMB1, TCEA1, CD24, SUPT5H, NFATC3, TERF2, CUL1, MYST3, AXIN1, ANAPC2, AR, TAF7, MED13, UIMC1, MED6, HDAC5, PKNOX1, BPTF, PSMA5, PSMC3, SMARCC2, TNK2, RBM15

7.98E-03

AR, CNBP, MORF4L2, ARNT2, STAT5B, MITF, TAF7, CYTL1, NAA15, CTCF, MED13, CRX, NR1H2, MED6, HDAC5, PKNOX1, BPTF, SMARCC2, TCEA1, SUPT5H, NFATC3, RBM15

HCRT, EIF2C2, MTDH, E2F6, TH1L, CTCF, NR1H2, AES, SUPT5H, EIF2B4, TERF2, NFX1, MYST3, ZNF281, DNMT3A, GTPBP4, NACC2, TAF7, SIRT4, UIMC1, HDAC5, ZNF238, BPTF, SMARCC2, RBM15 
Table III. Continued.

\begin{tabular}{|c|c|c|c|}
\hline Term & Count & P-value & Gene symbol \\
\hline $\begin{array}{l}\text { GO: } 0051254 \text { - positive } \\
\text { regulation of RNA } \\
\text { metabolic process }\end{array}$ & 22 & 8.70E-03 & $\begin{array}{l}\text { AR, CNBP, MORF4L2, ARNT2, STAT5B, MITF, TAF7, CYTL1, NAA15, CTCF, } \\
\text { MED13, CRX, NR1H2, MED6, HDAC5, PKNOX1, BPTF, SMARCC2, TCEA1, } \\
\text { SUPT5H, NFATC3, RBM15 }\end{array}$ \\
\hline $\begin{array}{l}\text { GO:0045934 - negative } \\
\text { regulation of nucleic } \\
\text { acid metabolic process }\end{array}$ & 23 & $8.74 \mathrm{E}-03$ & $\begin{array}{l}\text { ZNF281, DNMT3A, HCRT, GTPBP4, NACC2, MTDH, E2F6, TH1L, TAF7, } \\
\text { SIRT4, CTCF, UIMC1,NR1H2, HDAC5, AES, ZNF } 238, B P T F, \text { SMARCC2, } \\
\text { SUPT5H, RBM15, TERF2, MYST3, NFX1 }\end{array}$ \\
\hline $\begin{array}{l}\text { GO:0010556 - } \\
\text { regulation } \\
\text { of macromolecule } \\
\text { biosynthetic process }\end{array}$ & 89 & $9.86 \mathrm{E}-03$ & 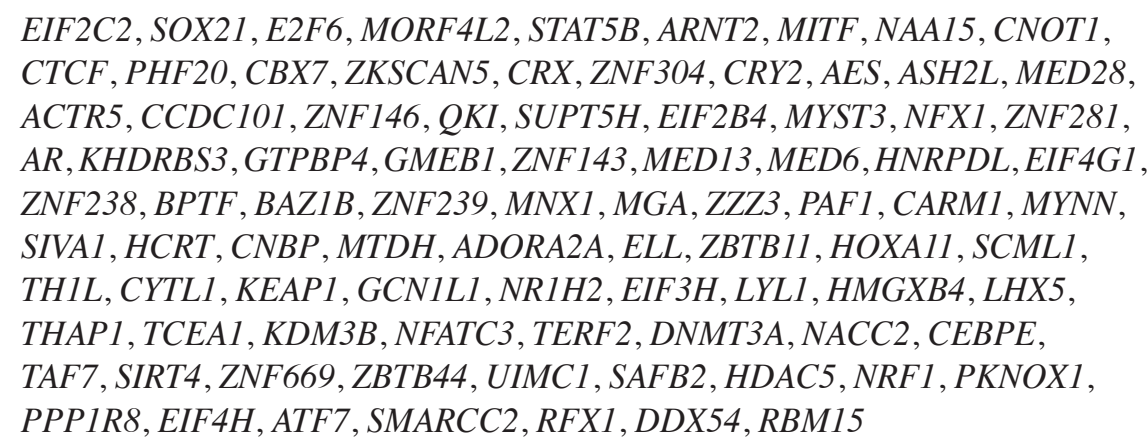 \\
\hline
\end{tabular}

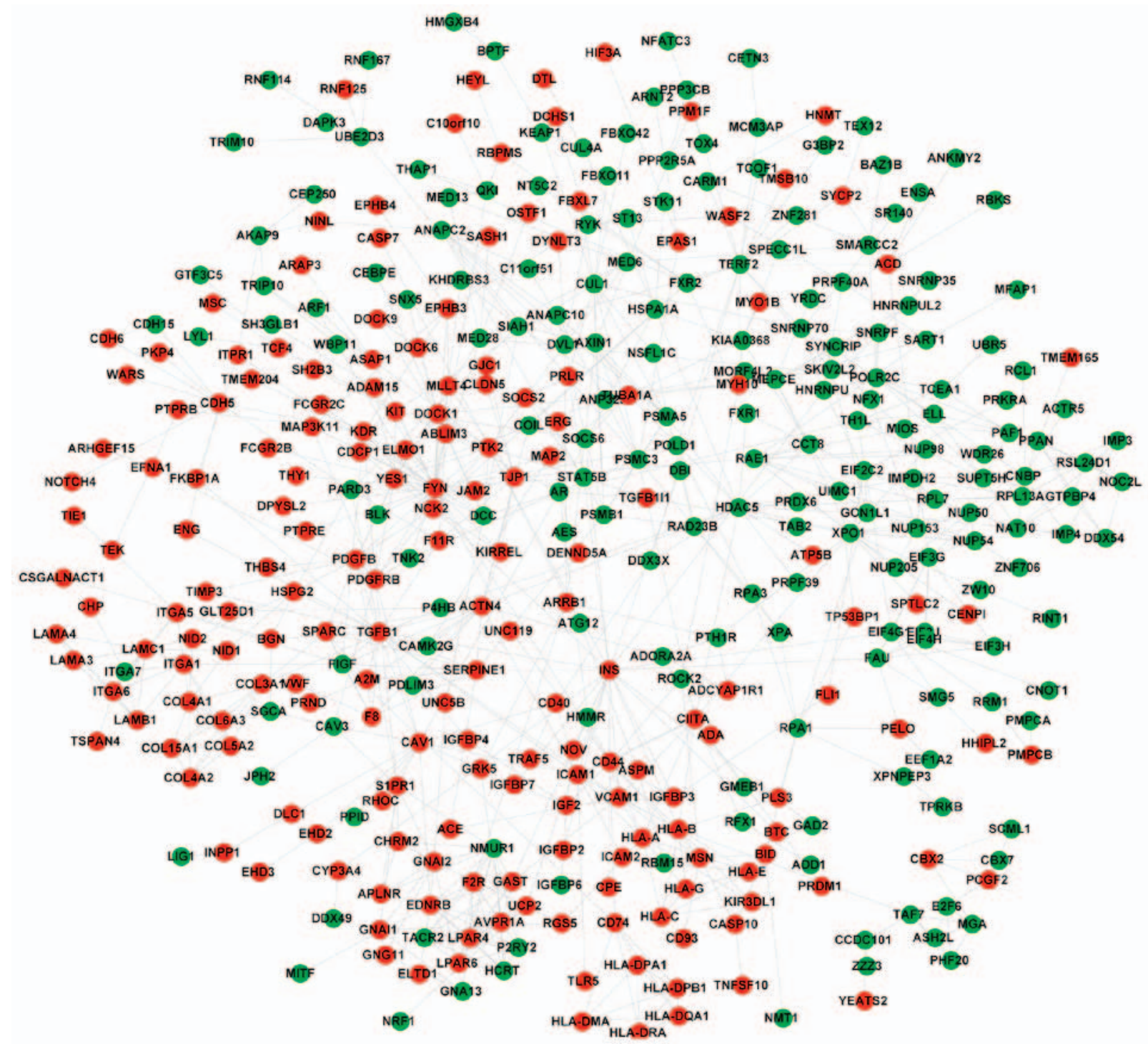

Figure 3. Protein-protein interaction network constructed for the differentially expressed genes. Red and green represent upregulated and downregulated genes, respectively. 
Table IV. The KEGG pathways significant enriched for the downregulated genes.

\begin{tabular}{|c|c|c|c|}
\hline Term & Count & P-value & Gene symbol \\
\hline $\begin{array}{l}\text { hsa05416: Viral } \\
\text { myocarditis }\end{array}$ & 15 & $7.85 \mathrm{E}-08$ & $\begin{array}{l}\text { BID, ICAM1, CAV1, HLA-A, HLA-C, CD40, HLA-B, HLA-E, HLA-DMA, } \\
\text { HLA-DQA1, HLA-G, FYN, HLA-DPA1, HLA-DPB1, MYH10, HLA-DRA }\end{array}$ \\
\hline $\begin{array}{l}\text { hsa04510: Focal } \\
\text { adhesion }\end{array}$ & 22 & $3.70 \mathrm{E}-06$ & $\begin{array}{l}C A V 1, C O L 4 A 2, C O L 4 A 1, A C T N 4, \text { PDGFB, COL3A1, ITGA1, COL5A2, } \\
\text { KDR, VWF, PTK2, LAMA4, LAMA3, DOCK1, ITGA6, ITGA5, FYN, } \\
\text { COL6A3, PDGFRB, LAMC1, LAMB1, THBS4 }\end{array}$ \\
\hline hsa04144: Endocytosis & 16 & $1.44 \mathrm{E}-03$ & $\begin{array}{l}P S D 3, A S A P 2, H L A-A, A S A P 1, H L A-C, K I T, H L A-B, H L A-E, H L A-G, \\
K D R, A R R B 1, G R K 5, A R A P 3, E H D 2, E H D 3, F 2 R, E H D 4\end{array}$ \\
\hline
\end{tabular}
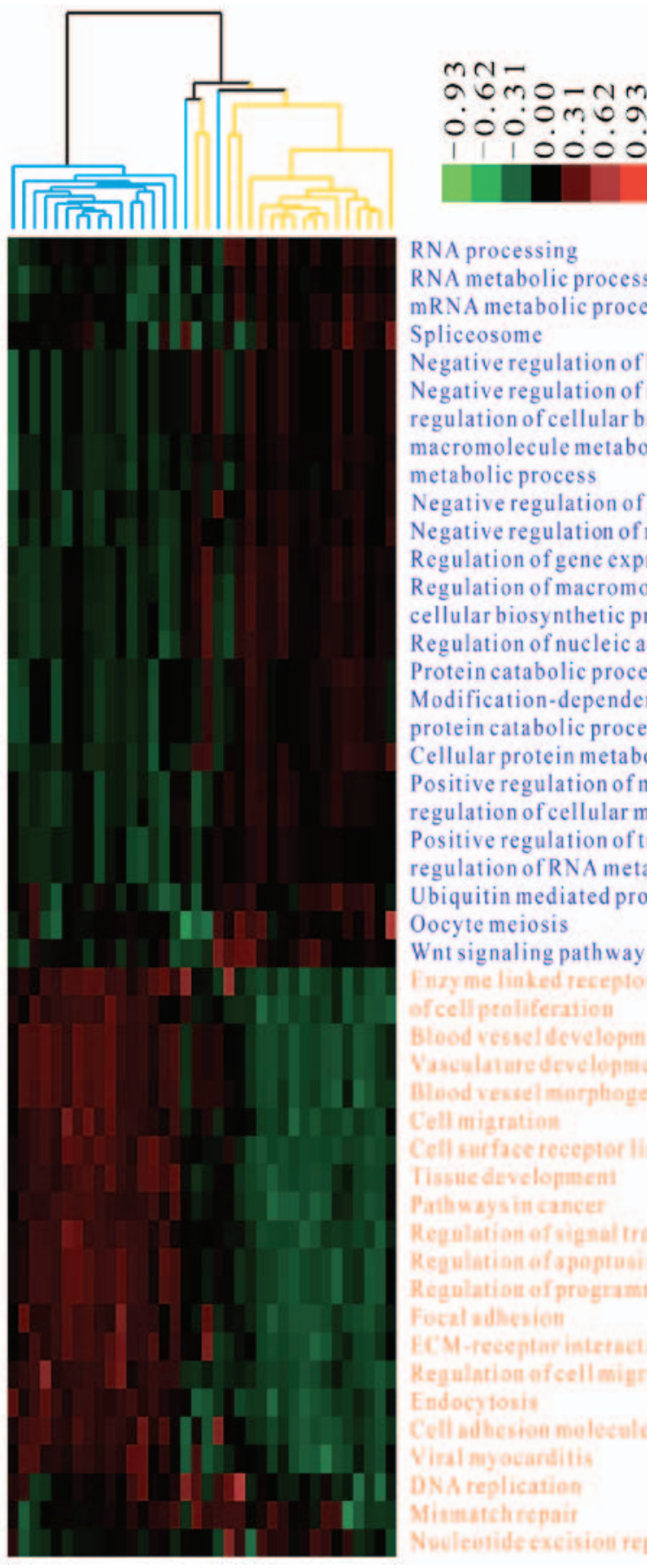

RNA processing

RNA metabolic process

mRNA metabolic process

Spliceosome

Negative regulation of biosynthetic process

Negative regulation of macromolecule biosynthetic process Negative

regulation of cellular biosynthetic process Negative regulation of

macromolecule metabolic process Negative regulation of cellular

metabolic process

Negative regulation of gene expression

Negative regulation of metabolic process

Regulation of gene expression

Regulation of macromolecule biosynthetic process Regulation of

cellular biosynthetic process

Regulation of nucleic acid metabolic process

Protein catabolic process

Modification-dependent macromolecule catabolic process Cellular protein catabolic process

Cellular protein metabolic process

Positive regulation of macromolecule metabolic process Positive

regulation of cellular metabolic process

Positive regulation of transcription, DNA-dependent Positive

regulation of RNA metabolic process

Ubiquitin mediated proteolysis

Oocyte meiosis

Wnt signaling pathway

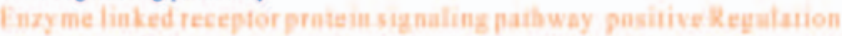

of cell proliferation

Blood veseldevelopment

Vascularuredevelopment

Mliod vesel murnhotenesit

Cell miaration

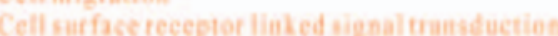

nisucdevelopmeni

Pathuavsincancer

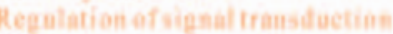

Regulation afomoptuan

Reauhation of programmed celldeatb

Focal adhesion

HCM-recentar isterautan

Kegulation of cell migration

Endocytonit:

Cull nathesou moleculen(CAMs)

Viral neyocarditis

ONA replication

Misuarchrepais

Nouleutideceision repait

Figure 4. Heat map of hierarchical clustering analysis with functional terms as features. Horizontal and vertical axes represent osteosarcoma biopsy specimens before (yellow)/after (blue) metastasis and the functional terms (red and blue represent upregulation and downregulation, respectively. 


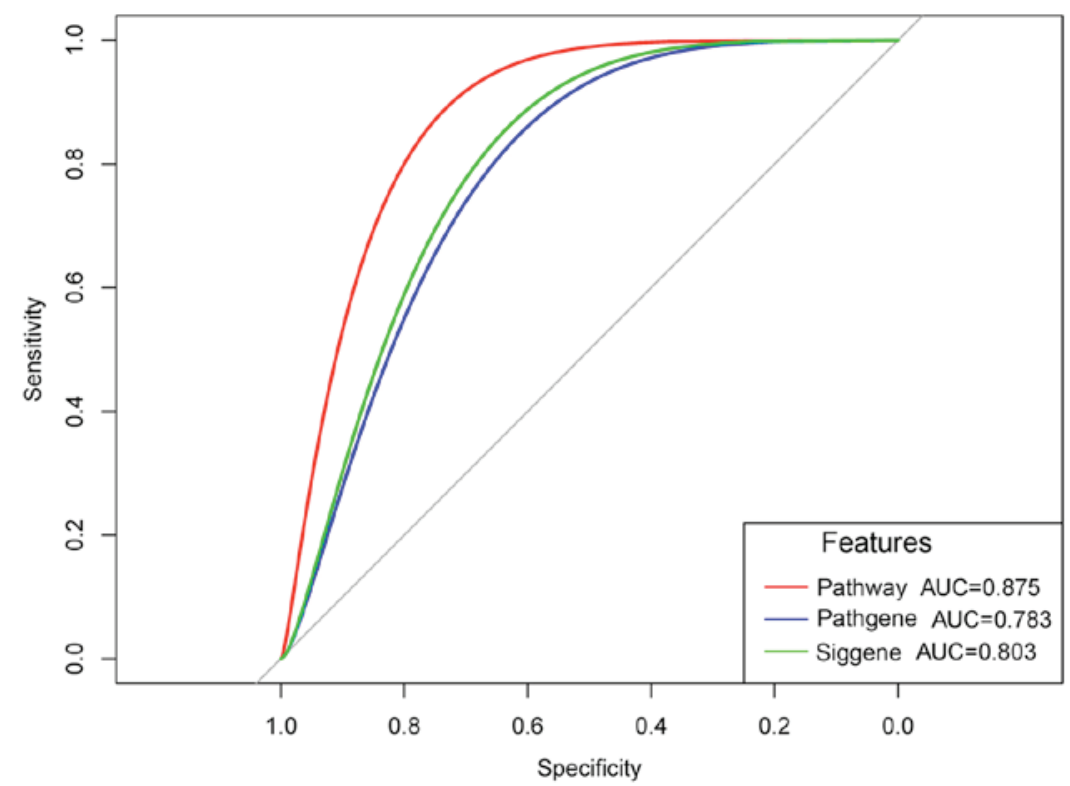

Figure 5. Receiver operating characteristic curves. Red curve indicates the prediction accuracies of the recurrent risk-associated terms (pathway); blue curve indicates the prediction accuracies of the genes enriched in the recurrent risk-associated terms (Pathgene); green curve indicates the prediction accuracies of the differentially expressed genes (Siggene). AUC, area under the curve.

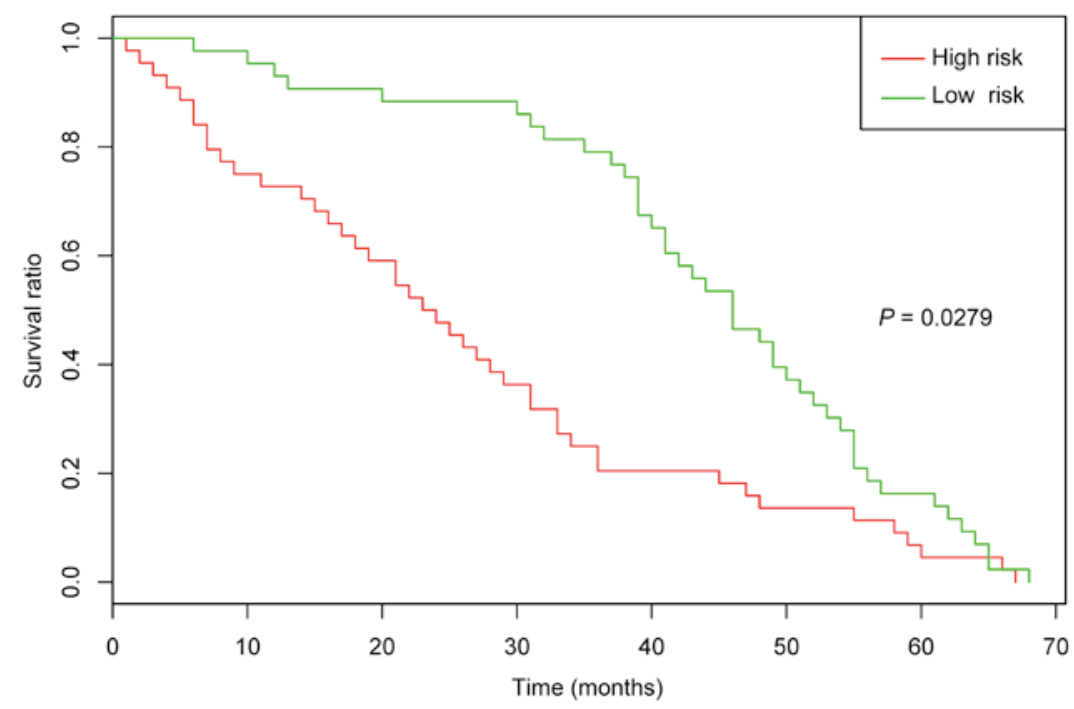

Figure 6. Kaplan-Meier survival curves. Red and green represent the predicted high- and low-risk groups, respectively.

repair, the Wnt signaling pathway, and cell migration were among the top 25 terms exhibiting significant differences. ROC curves indicated that the metastasis-associated terms optimized the number of characteristics without reducing the prediction accuracy. Additionally, the KM survival curve indicated that the survival times of the samples with significantly different metastasis-associated terms also demonstrated significant changes. In addition, the metastasis-associated terms affected drug sensitivity and had better predictive effect for OS specimens with obvious resistance.

The nucleotide excision repair pathway, which repairs bulky lesions and is correlated with platinum-based chemotherapy and tumor progression $(30,31)$. ERCC excision repair 2, TFIIH core complex helicase subunit, a member of the nucleotide excision repair pathway, rs1799793 is a marker of OS and is associated with the survival of OS patients following platinum therapy (32). The Wnt signaling pathway has aberrant activation in OS, which is associated with the development and progression of this type of bone malignancy $(33,34)$. The genes involved in Wnt and other Wnt signaling pathways have frequent deletions, indicating that the Wnt signaling pathway is genetically inactivated in patients with OS (35). Therefore, nucleotide excision repair and Wnt signaling pathways may be involved in the pathogenesis of OS.

The present study indicated that ICAMI, PDGFB and $P D G F R B$ were enriched in cell migration and regulation of cell migration. Via promoting the expression of ICAMI, chemokine (C-X3-C motif) ligand 1 (termed fractalkine) contributes to migration and metastasis of OS cells, and thus represents a promising therapeutic target for inhibiting OS metastasis (36). 
Table V. The top 25 terms with significant difference in the osteosarcoma biopsy specimens before/after metastasis.

\begin{tabular}{|c|c|}
\hline Term & P-value \\
\hline Blood vessel development & $3.01 \mathrm{E}-05$ \\
\hline Vasculature development & $8.11 \mathrm{E}-06$ \\
\hline RNA processing & $3.97 \mathrm{E}-05$ \\
\hline $\begin{array}{l}\text { Positive regulation of macromolecule } \\
\text { metabolic process }\end{array}$ & $1.87 \mathrm{E}-07$ \\
\hline Negative regulation of gene expression & $6.75 \mathrm{E}-05$ \\
\hline Regulation of cell migration & $2.15 \mathrm{E}-05$ \\
\hline Blood vessel morphogenesis & $1.77 \mathrm{E}-05$ \\
\hline DNA replication & $3.78 \mathrm{E}-05$ \\
\hline Nucleotide excision repair & $1.31 \mathrm{E}-05$ \\
\hline ECM-receptor interaction & $5.27 \mathrm{E}-05$ \\
\hline Viral myocarditis & $3.09 \mathrm{E}-04$ \\
\hline Protein catabolic process & 7.33E-04 \\
\hline Oocyte meiosis & $9.26 \mathrm{E}-04$ \\
\hline Negative regulation of metabolic process & $1.85 \mathrm{E}-03$ \\
\hline Mismatch repair & $2.12 \mathrm{E}-03$ \\
\hline Negative regulation of cellular biosynthetic process & $2.32 \mathrm{E}-03$ \\
\hline Wnt signaling pathway & $2.32 \mathrm{E}-03$ \\
\hline mRNA metabolic process & $3.70 \mathrm{E}-03$ \\
\hline Tissue development & $5.16 \mathrm{E}-03$ \\
\hline Cell migration & $5.56 \mathrm{E}-03$ \\
\hline RNA metabolic process & $7.41 \mathrm{E}-03$ \\
\hline Enzyme linked receptor protein signaling pathway & $8.33 \mathrm{E}-03$ \\
\hline Focal adhesion & 8.77E-03 \\
\hline Pathways in cancer & $9.26 \mathrm{E}-03$ \\
\hline Regulation of apoptosis & $9.52 \mathrm{E}-03$ \\
\hline
\end{tabular}

Via the PI3K/Akt signaling pathway, ICAM1 expression is upregulated by amphiregulin and thus leads to enhanced cell metastasis of OS $(37,38)$. Kubo et al (39) demonstrate that the expression levels of $P D G F$ and $P D G F R$ potentially predict the prognosis of OS. Takagi et al (40) observed that platelets promote PDGF function in the proliferation of OS cells via activation of the PDGFR-Akt signaling axis. Thus, ICAM1, PDGFB and $P D G F R B$ may act in OS via cell migration and regulation of cell migration. In the PPI network, there were various interactions (including ICAM1-TGFB1, TGFB1-PDGFB, and PDGFB-PDGFRB). Thus, ICAM1, $P D G F B$ and $P D G F R B$ function in OS via interacting with other genes.

Furthermore, TGFB1 was enriched in cell migration and regulation of cell migration. The serum level of TGFB in OS patients with metastasis is higher than that in OS patients without metastasis, indicating that $T G F B$ may be important in OS (41). TGFB2 activity is inhibited by lumican, which subsequently mediates cell adhesion of OS by regulating integrin- $\beta 1$, phosphorylated SMAD family member 2 (SMAD2) and phosphorylated focal adhesion kinase (42). Wu et al (43) report that the $29 \mathrm{~T}>\mathrm{C}$ single nucleotide polymorphism of the TGFB1 gene is correlated with the incidence and invasion of OS. The TGFB/SMAD3 and p53 signaling pathways are critical for the doxorubicin-induced cytotoxicity in OS cells (44). Antisense
TGFBl inhibits matrix metallopeptidase 2 and urokinase expression levels, which suppresses the invasion and metastasis of OS cells (45). Thus, TGFBI contribute to the metastasis of OS via cell migration and regulation of cell migration.

Limited to the number of collected samples, we cannot validate the results of this study in clinical samples. However, we believe that these results based on large data analysis could provide valuable clues for the study of the pathogenesis of metastasis or may aid in the development of novel treatment strategies for OS.

In conclusion, a total of 840 DEGs were identified in the case group. In addition, nucleotide excision repair and the Wnt signaling pathway, as well as cell migration and regulation of cell migration involving ICAM1, PDGFB, PDGFRB and $T G F B 1$ may represent the metastasis-associated pathways of OS.

\section{References}

1. Luetke A, Meyers PA, Lewis I and Juergens H: Osteosarcoma treatment - where do we stand? A state of the art review. Cancer Treat Rev 40: 523-532, 2014.

2. Ottaviani G, Jaffe N, Eftekhari F, Raymond AK and Yasko AW: Pediatric and Adolescent Osteosarcoma. Springer, New York, NY, 2010

3. Ritter J and Bielack SS: Osteosarcoma. Ann Oncol 21 (Suppl 7): vii320-vii325, 2010

4. Geller DS and Gorlick R: Osteosarcoma: a review of diagnosis, management, and treatment strategies. Clin Adv Hematol Oncol 8: 705-718, 2010.

5. Mavrogenis AF, Abati CN, Romagnoli C and Ruggieri P: Similar survival but better function for patients after limb salvage versus amputation for distal tibia osteosarcoma. Clin Orthop Relat Res 470: 1735-1748, 2012.

6. Dong Y, Liang G, Yuan B, Yang C, Gao R and Zhou X: MALAT1 promotes the proliferation and metastasis of osteosarcoma cells by activating the PI3K/Akt pathway. Tumour Biol 36: 1477-1486, 2015.

7. Zhang JH, Kang XH, Lu P, Miao ZH, Sun GS, Cao XJ and Cao F: Expression of long non-coding RNA MALAT1 in osteosarcoma and its effect on invasiveness and metastatic potential of osteosarcoma cells. Zhonghua Bing Li Xue Za Zhi 45: 561-565, 2016 (In Chinese).

8. Hou CH, Lin FL, Tong KB, Hou SM and Liu JF: Transforming growth factor alpha promotes osteosarcoma metastasis by ICAM-1 and PI3K/Akt signaling pathway. Biochem Pharmacol 89: 453-463, 2014.

9. Zhao Z, Wu MS, Zou C, Tang Q, Lu J, Liu D, Wu Y, Yin J, Xie X, Shen J, et al: Downregulation of MCT1 inhibits tumor growth, metastasis and enhances chemotherapeutic efficacy in osteosarcoma through regulation of the NF- $\kappa \mathrm{B}$ pathway. Cancer Lett 342: 150-158, 2014

10. Zhao S, Kurenbekova L, Gao Y, Roos A, Creighton CJ, Rao P, Hicks J, Man TK, Lau C, Brown AM, et al: NKD2, a negative regulator of Wnt signaling, suppresses tumor growth and metastasis in osteosarcoma. Oncogene 34: 5069-5079, 2015.

11. Sun XZ, Liao Y and Zhou CM: NKD2 a novel marker to study the progression of osteosarcoma development. Eur Rev Med Pharmacol Sci 20: 2799-2804, 2016.

12. Qian M, Yang X, Li Z, Jiang C, Song D, Yan W, Liu T, Wu Z, Kong J, Wei H, et al: p50-associated COX-2 extragenic RNA (PACER) overexpression promotes proliferation and metastasis of osteosarcoma cells by activating COX-2 gene. Tumour Biol 37: 3879-3886, 2016.

13. Kelly AD, Haibe-Kains B, Janeway KA, Hill KE, Howe E, Goldsmith J, Kurek K, Perez-Atayde AR, Francoeur N, Fan JB, et al: MicroRNA paraffin-based studies in osteosarcoma reveal reproducible independent prognostic profiles at 14q32. Genome Med 5: 2, 2013.

14. Ritchie ME, Phipson B, Wu D, Hu Y, Law CW, Shi W and Smyth GK: Limma powers differential expression analyses for RNA-sequencing and microarray studies. Nucleic Acids Res 43: e47, 2015. 
15. Demšar J, Curk T, Erjavec A, Gorup Č, Hočevar T, Milutinovič M, Možina M, Polajnar M, Toplak M, Starič A, et al: Orange: Data mining toolbox in Python. J Mach Learn Res 14: 2349-2353, 2013.

16. Man D, Uda K, Ito Y and Nakano K: Accelerating computation of Euclidean distance map using the GPU with efficient memory access. Int J Parallel Emergent Distrib Syst 28: 383-406, 2013.

17. Nahler G: Pearson correlation coefficient. Springer Top Signal Process 2: 1-4, 2009.

18. Zha W, Li M and Fu Y: Empirical analysis of highway traffic accident in average linkage clustering method. ECJTU, 2010

19. Kohonen T: The self-organization map. Adv Inf Knowl Process 1: 3-17, 2007

20. Tweedie S, Ashburner M, Falls K, Leyland P, McQuilton P, Marygold S, Millburn G, Osumi-Sutherland D, Schroeder A, Seal R, et al; FlyBase Consortium: FlyBase: Enhancing Drosophila gene ontology annotations. Nucleic Acids Res 37: D555-D559, 2009.

21. Kanehisa M and Goto S: KEGG: Kyoto encyclopedia of genes and genomes. Nucleic Acids Res 28: 27-30, 2000.

22. Huang DW, Sherman BT, Tan Q, Kir J, Liu D, Bryant D, Guo Y, Stephens R, Baseler MW, Lane HC, et al: DAVID Bioinformatics Resources: Expanded annotation database and novel algorithms to better extract biology from large gene lists. Nucleic Acids Res 35: W169-175, 2007.

23. Chatr-Aryamontri A, Breitkreutz BJ, Oughtred R, Boucher L, Heinicke S, Chen D, Stark C, Breitkreutz A, Kolas N, O'Donnell L, et al: The BioGRID interaction database: 2015 update. Nucleic Acids Res 43: D470-D478, 2015.

24. Keshava Prasad TS, Goel R, Kandasamy K, Keerthikumar S, Kumar S, Mathivanan S, Telikicherla D, Raju R, Shafreen B, Venugopal A, et al: Human Protein Reference Database - 2009 update. Nucleic Acids Res 37: D767-D772, 2009.

25. Saito R, Smoot ME, Ono K, Ruscheinski J, Wang PL, Lotia S, Pico AR, Bader GD and Ideker T: A travel guide to Cytoscape plugins. Nat Methods 9: 1069-1076, 2012.

26. Langfelder P, Mischel PS and Horvath S: When is hub gene selection better than standard meta-analysis? PLoS One 8 : e61505, 2013

27. Roush ET, Das T and Nandana P: Cluster software upgrades. Journal 2009.

28. May WL: Kaplan-Meier survival analysis. Encyclopedia of Cancer 1934-1937, 2011.

29. Yoshii T, Geng Y, Peyton S, Mercurio AM and Rotello VM: Biochemical and biomechanical drivers of cancer cell metastasis, drug response and nanomedicine. Drug Discov Today 21: 1489-1494, 2016.

30. Stoehlmacher J, Park DJ, Zhang W, Yang D, Groshen S, Zahedy S and Lenz HJ: A multivariate analysis of genomic polymorphisms: Prediction of clinical outcome to 5-FU/oxaliplatin combination chemotherapy in refractory colorectal cancer. Br J Cancer 91: 344-354, 2004.

31. Reed E: Platinum-DNA adduct, nucleotide excision repair and platinum based anti-cancer chemotherapy. Cancer Treat Rev 24: 331-344, 1998
32. Biason P, Hattinger CM, Innocenti F, Talamini R, Alberghini M, Scotlandi K, Zanusso C, Serra M and Toffoli G: Nucleotide excision repair gene variants and association with survival in osteosarcoma patients treated with neoadjuvant chemotherapy. Pharmacogenomics J 12: 476-483, 2012.

33. Cai Y, Cai T and Chen Y: Wnt pathway in osteosarcoma, from oncogenic to therapeutic. J Cell Biochem 115: 625-631, 2014.

34. Lin $\mathrm{CH}$, Ji T, Chen $\mathrm{CF}$ and Hoang BH: Wnt signaling in osteosarcoma. Adv Exp Med Biol 804: 33-45, 2014.

35. Du X, Yang J, Yang D, Tian W and Zhu Z: The genetic basis for inactivation of Wnt pathway in human osteosarcoma. BMC Cancer 14: 450, 2014.

36. Liu JF, Tsao YT and Hou CH: Fractalkine/CX3CL1 induced intercellular adhesion molecule-1-dependent tumor metastasis through the CX3CR1/PI3K/Akt/NF- $\kappa$ B pathway in human osteosarcoma. Oncotarget 8: 54136-54148, 2016.

37. Liu JF, Tsao YT and Hou CH: Amphiregulin enhances intercellular adhesion molecule-1 expression and promotes tumor metastasis in human osteosarcoma. Oncotarget 6: 40880-40895, 2015.

38. Lin YM, Chang ZL, Liao YY, Chou MC and Tang CH: IL-6 promotes ICAM-1 expression and cell motility in human osteosarcoma. Cancer Lett 328: 135-143, 2013.

39. Kubo T, Piperdi S, Rosenblum J, Antonescu CR, Chen W, Kim HS, Huvos AG, Sowers R, Meyers PA, Healey JH, et al: Platelet-derived growth factor receptor as a prognostic marker and a therapeutic target for imatinib mesylate therapy in osteosarcoma. Cancer 112: 2119-2129, 2008.

40. Takagi S, Takemoto A, Takami M, Oh-Hara T and Fujita N: Platelets promote osteosarcoma cell growth through activation of the platelet-derived growth factor receptor-Akt signaling axis. Cancer Sci 105: 983-988, 2014.

41. Xu S, Yang S, Sun G, Huang W and Zhang Y: Transforming growth factor-beta polymorphisms and serum level in the development of osteosarcoma. DNA Cell Biol 33: 802-806, 2014.

42. Nikitovic D, Chalkiadaki G, Berdiaki A, Aggelidakis J, Katonis P, Karamanos NK and Tzanakakis GN: Lumican regulates osteosarcoma cell adhesion by modulating TGF 32 activity. Int J Biochem Cell Biol 43: 928-935, 2011

43. Wu Y, Zhao J and He M: Correlation between TGF- $\beta 1$ gene 29 $\mathrm{T}>\mathrm{C}$ single nucleotide polymorphism and clinicopathological characteristics of osteosarcoma. Tumour Biol 36: 5149-5156, 2015.

44. Sun Y, Xia P, Zhang H, Liu B and Shi Y: P53 is required for Doxorubicin-induced apoptosis via the TGF-beta signaling pathway in osteosarcoma-derived cells. Am J Cancer Res 6: 114-125, 2015.

45. Bao TZ, Zao HW and Zheng QX, Liu W and Liu Y: Effects of antisense transforming growth factor- $\beta 1$ on the factors related to metastasis in osteosarcoma. Chin J Exp Surg 4: 477-478, 2005.

This work is licensed under a Creative Commons Attribution-NonCommercial-NoDerivatives 4.0 International (CC BY-NC-ND 4.0) License. 